\title{
Nesfatin-1 inhibits proliferation and enhances apoptosis of human adrenocortical H295R cells
}

\author{
Manjunath Ramanjaneya,2, Bee K Tan ${ }^{1,3}$, Marcin Rucinski ${ }^{4}$, Mohamed Kawan', \\ Jiamiao Hu', Jaspreet Kaur', Vanlata H Patel', Ludwik K Malendowicz ${ }^{4}$, \\ Hanna Komarowska ${ }^{5}$, Hendrik Lehnert ${ }^{1,6}$ and Harpal S Randeva ${ }^{1,7,8}$ \\ ${ }^{1}$ Warwick Medical School, University of Warwick, Coventry CV4 7AL, UK \\ ${ }^{2}$ Interim Translational Research Institute, Academic Health System, Hamad Medical Corporation, Doha, Qatar \\ ${ }^{3}$ Department of Obstetrics and Gynaecology, Birmingham Heartlands Hospital, Heart of England NHS Foundation \\ Trust, Birmingham, UK \\ ${ }^{4}$ Department of Histology and Embryology, Poznan University of Medical Sciences, Poznan, Poland \\ ${ }^{5}$ Department of Endocrinology, Metabolism and Internal Medicine, University of Medical Sciences, \\ 16 Karol Marcinkowski, Poznan, Poland \\ ${ }^{6} 1$ st Medical Department, University of Lübeck Medical School, Lübeck, Germany \\ ${ }^{7}$ Department of Diabetes, Endocrinology and Metabolism, University Hospital, Coventry CV2 2DX, UK \\ ${ }^{8}$ Aston Medical Research Institute, School of Life and Health Sciences, Aston University, Birmingham, UK
}

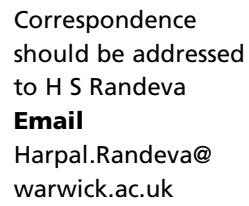

\begin{abstract}
NUCB2/nesfatin and its proteolytically cleaved product nesfatin-1 are recently discovered anorexigenic hypothalamic neuroproteins involved in energy homeostasis. It is expressed both centrally and in peripheral tissues, and appears to have potent metabolic actions. NUCB2/nesfatin neurons are activated in response to stress. Central nesfatin-1 administration elevates circulating ACTH and corticosterone levels. Bilateral adrenalectomy increased NUCB2/nesfatin mRNA levels in rat paraventricular nuclei. To date, studies have not assessed the effects of nesfatin-1 stimulation on human adrenocortical cells. Therefore, we investigated the expression and effects of nesfatin-1 in a human adrenocortical cell model (H295R). Our findings demonstrate that NUCB2 and nesfatin-1 are expressed in human adrenal gland and human adrenocortical cells (H295R). Stimulation with nesfatin-1 inhibits the growth of $\mathrm{H} 295 \mathrm{R}$ cells and promotes apoptosis, potentially via the involvement of Bax, BCL-XL and BCL-2 genes as well as ERK $1 / 2, \mathrm{p} 38$ and JNK1/2 signalling cascades. This has implications for understanding the role of NUCB2/nesfatin in adrenal zonal development. NUCB2/nesfatin may also be a therapeutic target for adrenal cancer. However, further studies using in vivo models are needed to clarify these concepts.
\end{abstract}

\section{Key Words}

- adrenal cortex

- apoptosis

- nesfatin-1

- NUCB2

\section{Introduction}

Optimal development of adrenal tissue requires a balance between cell proliferation and apoptosis (programmed cell death); apoptosis removes harmful, damaged or unwanted cells. Within the adrenal gland, constant dynamic changes control the rate of cell growth as a result of alterations in physiological and pathophysiological conditions (Keegan \& Hammer 2002, Kirschner 2002). Regulation of adrenocortical cellular growth is a critical process in adrenal remodelling, especially during embryonic and postnatal development in humans and primates

Published by Bioscientifica Ltd
Journal of Endocrinology (2015) 226, 1-11 
(Sucheston \& Cannon 1968, Ducsay et al. 1991). Cell death by apoptosis in the adrenal gland is one of the most common causes of adrenal failure in adrenocortical atrophy (Maisey \& Lessof 1969). Many centrally active neuropeptides and molecules, including neuropeptide $\mathrm{Y}$, ghrelin, adipokines such as TNF $\alpha$, regulate adrenocortical cell growth by altering intracellular signalling cascades leading to dysregulated growth of adrenocortical cells.

Nesfatin-1 is a recently discovered hypothalamic polypeptide derived from its precursor protein nesfatin/ nucleobindin2 (NUCB2; Oh-I et al. 2006). Nesfatin-1 is abundantly expressed in various regions of the hypothalamus and the regions of the brain involved in the regulation of food intake (Elmquist et al. 2005). NUCB2/ nesfatin neurons are activated in response to stress, and central administration of nesfatin-1 elevates circulating adrenocorticotrophin and corticosterone (Stengel \& Taché 2011). Bilateral adrenalectomy resulted in increased NUCB2/nesfatin mRNA levels in the paraventricular nuclei of rats, suggesting the importance of NUCB2/nesfatin in the regulation of the hypothalamic-pituitaryadrenal axis (Könczöl et al. 2010). NUCB2/nesfatin is also widely expressed in peripheral tissues including the stomach, pancreas as well as in adipose tissue, and regulates various physiological and pathological processes; the main function being suppression of food intake via a leptin independent pathway (Oh-I et al. 2006, Shimizu et al. 2009). Recent studies have associated NUCB2/nesfatin with various forms of cancer. The expression of NUCB2/nesfatin was found to be higher in breast and prostate cancer patients (Suzuki et al. 2012, Zhang et al. 2013a). A positive correlation was observed between NUCB2/nesfatin, seminal vesicle invasion, lymph node metastasis, angiolymphatic invasion and a higher Gleason score in prostate cancer. More importantly, a poor overall survival rate was observed in patients with prostate cancer patients who had higher NUCB2/ nesfatin levels (Zhang et al. 2013a,b, 2014). However conflicting observations were found in lung cancer patients, with circulating nesfatin-1 concentrations being lower in lung cancer patients who have undergone weight loss (Cetinkaya et al. 2013). In another study, nesfatin-1 inhibited the proliferation of a human ovarian epithelial carcinoma cell line (Xu et al. 2013). We have previously reported nesfatin-1 as a novel adipokine produced from adipocytes and that the circulating and cerebrospinal fluid levels are altered in obese individuals (Ramanjaneya et al. 2010, Tan et al. 2011). Adipokines have been implicated in the pathophysiology of metabolic disorders (Lewandowski et al. 2008, Tan et al. 2009,
Adya et al. 2012, Randeva et al. 2012), and have been shown to have direct effects on the adrenal glands (Kargi \& Iacobellis 2014). Given the reports from Ehrhart-Bornstein et al. (2004) demonstrating the existence of intra-adrenal fat, and that the adipokines released regulate adrenal secretion in an autocrine and paracrine manner, we aim to investigate the expression of NUCB2/nesfatin in human adrenal gland and human adrenocortical cells (H295R), as well as the effects of nesfatin- 1 on H295R cells. H295R cells are pluripotent adrenocortical cells capable of producing all major zone-specific adrenal steroids (Rainey et al. 1994).

\section{Materials and methods}

\section{Biochemical reagents}

Human nesfatin-1 peptide and nesfatin-1 antibody was obtained from Phoenix Pharmaceuticals, Inc. (Belmont, CA, USA). Insulin-transferrin-selenium (ITS) and Ultroser $G$ were purchased from Pall Life Sciences (Cergy, France). Growth supplement for H295R cells was obtained from Sigma-Aldrich. Accutase required for splitting cells was bought from Cellworks (Buckingham, UK). ECL plus western blotting detection reagents was obtained from GE Healthcare (Little Chalfont, UK). Agarose was obtained from MBI Fermentas, Helena Biosciences (Sunderland, UK). phospo-ERK1/2, phospo-p38, phospo-JNK1/2, ERK1/2, p38 and JNK1/2 antibodies were purchased from Cell Signaling Technology, (Beverly, MA, USA). Polyclonal HRP-conjugated goat anti-rabbit, anti-mouse immunoglobulin/HRP was obtained from Dako (Ely, UK). Precision Plus Protein Standard was obtained from Bio-Rad Laboratories Ltd. A PVDF membrane was obtained from GE Healthcare. All of the primers were obtained from TAGN (Gateshead, UK). Human adrenal glands were obtained under ethical approval, Department of Endocrinology, Metabolism and Internal Medicine, Karol Marcinkowski University of Medical Sciences (Poznan, Poland), bioethics approval number: 556/13.

\section{Cell culture}

H295R human adrenocortical cells were cultured in H295R complete media containing DMEM/F12 (1:1) supplemented with $2 \%$ Ultroser G and ITS, in six-well plates (BD Biosciences Discovery Labware (Bedford, MA, USA) for $24 \mathrm{~h}$ after reaching confluence. Media was replaced with $2 \mathrm{ml}$ fresh media containing different agents and cultured for $<1 \mathrm{~h}$ for MAPK experiments, 4 and $24 \mathrm{~h}$ for steroidogenic acute regulatory protein (StAR) gene

Published by Bioscientifica Ltd. 
expression studies. DNA fragmentation and apoptosis studies were done following $24 \mathrm{~h}$ stimulation with nesfatin-1 in 96-well plates. At the end of the incubation period, cells were washed with ice-cold PBS and subjected to RNA extraction and analysis as described in the following section.

Y1 mouse adrenal tumour cells (a gift from Prof. Henrik Oster, University of Lübeck, Germany) was grown in DMEM supplemented with 15\% horse serum, $2.5 \%$ fetal bovine serum and $1 \%$ penicillin/streptomycin. The cells were incubated in a humidified atmosphere at $5 \% \mathrm{CO}_{2}$ at $37^{\circ} \mathrm{C}$.

\section{Total RNA extraction and cDNA synthesis}

Total RNA was extracted using the Qiagen RNeasy Mini Kit (Qiagen Ltd), according to the manufacturer's guidelines. The purity of the extracted RNA was measured by a NanoDrop spectrophotometer (Labtech International, Ringmer, UK). A set concentration of RNA was reverse transcribed into cDNA, using M-MuLV Reverse Transcriptase (Fermentas, York, UK) and random hexamers (Promega) as primers.

\section{RT-PCR}

NUCB2 gene expression was measured by RT-PCR, using $1 \mu \mathrm{g}$ total RNA and random hexamer primers as RT primers. A control reaction that omitted reverse transcriptase was included to check for the presence of genomic DNA. The concentration of target mRNA were measured by RT followed by real-time PCR performed on a Applied Biosystems 7500 Fast Real-Time PCR System (Life Technologies Ltd., Paisley, Renfrewshire, UK), according to the manufacturer's instructions. For analysis, quantitative amounts of the gene of interest were standardized against the housekeeping gene GAPDH. Negative controls for all the reactions included preparations lacking cDNA or RNAlacking reverse transcriptase in place of the cDNA. The relative mRNA levels were expressed as a ratio using the 'Delta-delta method' for comparing relative expression results between treatments in real-time PCR (Pfaffl 2001). The sequences of the sense and anti-sense primers used were NUCB2: 5'-GCCAGAACGTGTTACGAGTC-3' and 5'-GTCCTCCACCTCATGTTCAG-3'; StAR: 5'-GGCTACTCAGCATCGACCTC- $3^{\prime}$ and 5'-CATCCCACTGTCACCAGATG-3'; GAPDH: 5'-TGAACGGGAAGCTCACTGG-3' and $5^{\prime}$-TCCACCACCCTGTTGCTGTA-3'; BCL-XL: $5^{\prime}$-ACT: GTG: CGT: GGA: AAG: CGTAG-3' and $5^{\prime}$-GGTTCTCCTGGTGGCAATG-3'; BCL2: 5'-GAGGTCACGGGGGCTAATT-3 and 5'-GAGGCTGGGCACATTTACTG-3'; Bax: 5'-ATGGAGCTGCAGAGGATGAT- $3^{\prime}$ and $5^{\prime}$-CAGTTGAAGTTGCCGTCAGA-3'; p53: 5'-GTGGAGTATTTGGATGACAGAAAC-3' and 5'-GTAGTTGTAGTGGATGGTGGTAC-3'. PCR products were stained with ethidium bromide and visualized by electrophoresis through $1.5 \%$ agarose gels. Sequencing of the PCR products confirmed the sequence identities. The housekeeping gene was selected following geNorm analyses of five to six housekeeping genes using the geNorm kit (Primer Design, Southampton, UK). The housekeeping gene that was stably expressed in H295R cells was selected as reference gene. The efficiency of primers used for RT-PCR in our manuscript was evaluated by performing a tenfold dilution series experiment. The efficiency of the RT-PCR was calculated from slope generated by ABI 7500 Software version 2.0.6 (Life Technologies). Efficiency of all the primers used in the study was between 90 and 100\%.

\section{Western blotting}

Protein lysates were prepared by adding equal amounts of Laemmli buffer to each well, and samples were denatured by sonication and boiling. Samples were separated by SDSPAGE (10\% resolving gel) and transferred to PVDF membranes at $100 \mathrm{~V}$ for $1 \mathrm{~h}$ in a transfer buffer containing $20 \mathrm{mM}$ Tris, $150 \mathrm{mM}$ glycine and $20 \%$ methanol. The PVDF membranes were incubated with primary antibody for nesfatin-1, phospo-ERK1/2, phospo-p38 and phospoJNK1/2 or total-ERK1/2, p38 and JNK1/2 antibodies at a 1:1000 dilution in Tris-buffered saline (TBS)-0.1\% Tween (TBST) and 5\% BSA overnight at $4{ }^{\circ} \mathrm{C}$. The membranes were washed, incubated with corresponding secondary anti-rabbit, HRP-conjugated antibody (1:2000) for $1 \mathrm{~h}$ at room temperature, and washed for $60 \mathrm{~min}$ with TBST. Antibody complexes were visualized using ECL Plus chemiluminescence detection kit. The densities were measured using a scanning densitometer coupled to scanning Software Scion Image (Scion Corporation, Frederick, MD, USA). Standard curves were generated to ensure linearity of signal intensity over the range of protein amounts loaded into gel lanes. Comparisons of densitometric signal intensities were made only within this linearity range.

\section{Immunofluorescent staining and immunohistochemistry}

For the animal studies, adult female Wistar rats were used. The animals were maintained under standardized conditions of light ( $14 \mathrm{~h}$ light:10 h darkness cycle,

Published by Bioscientifica Ltd 
illumination onset at $0600 \mathrm{~h}$ ) at $23^{\circ} \mathrm{C}$, with free access to standard pellets and tap water. Rats were sacrificed by decapitation; adrenals were immediately removed, and fixed in Bouin's solution. After fixation tissues were dehydrated in 70, 80, 95\% alcohol (45 min each), followed by three times incubation in 100\% alcohol ( $1 \mathrm{~h}$ each). This was further cleared in xylene $(2 \times, 1 \mathrm{~h}$ each). Then tissues where immersed in paraffin $(1 \mathrm{~h})$. Embedding of tissues was performed by a paraffin dispenser DP 500 (Bio-Optica, Milano, Italy). Immunofluorescence staining was performed as previously described (Ramanjaneya et al. 2010). The two-stage immunoperoxidase method with EnVision-HRP complex was used. Adrenals were fixed in Bouin's solution for $24 \mathrm{~h}$, embedded in paraffin and sectioned. 5-6 $\mu \mathrm{m}$-thick sections were deparaffinised and rehydrated. They were boiled in citrate buffer in three steps procedure (pH 6; 3, 3 and $2.5 \mathrm{~min}$ ). After each boiling step sections were cooled $(3 \times 20 \mathrm{~min})$. Further steps were performed in a humidified chamber at room temperature. In order to inhibit endogenous peroxidase activity slides were incubated in 3\% solution of hydrogen peroxide for $10 \mathrm{~min}$. Subsequently, non-specific antibody binding sites were blocked by incubation in goat serum for $30 \mathrm{~min}$. The sections were incubated with the primary antibody overnight at $4{ }^{\circ} \mathrm{C}$ polyclonal anti-nesfatin- 1 (Phoenix Pharmaceuticals, Inc.) antibody, dilution (1:200). Subsequently, the sections were washed in PBS $(5 \times 3 \mathrm{~min})$ and incubated with the secondary (peroxidase-conjugated) antibody for $60 \mathrm{~min}$ at $37^{\circ} \mathrm{C}$. Peroxidase activity was detected using the DAB technique (Liquid DAB substrate, chromogen system, Dako, Glostrup, Denmark). Nuclei were counterstained with haematoxylin. Control sections were similarly treated with omission of the primary antibody.

\section{Cortisol and aldosterone measurements}

Cells were cultured in six-well plates. Cells were starved overnight in serum-free media for $48 \mathrm{~h}$ before experiments. Cells were then washed and incubated in fresh serum-free media with either $100 \mathrm{nM}$ nesfatin-1 or forskolin or angiotensin II for the treatment group and with PBS for the control group at timepoints from 6 to $48 \mathrm{~h}$. At the end of each time point, the supernatant was removed and frozen immediately in liquid nitrogen. Cortisol and aldosterone content of media was determined from three different experiments using commercially available ELISA Kits (ALPCO, Salem, NH, USA), according to the manufacturer's instructions, and normalized to the total protein content. The protein concentrations of cell lysates were determined by the bicinchoninic acid protein quantification assay kit as per manufacturer's protocol (Thermo Scientific, Rockford, MD, USA). The inter- and intra-assay coefficients of variation were $<7 \%$.

\section{Cell proliferation assay}

H295R and mouse Y1 cells were cultured for $24 \mathrm{~h}$ in complete media in 96 wells $\left(1 \times 10^{4}\right.$ cells/well in quadruplet). Prior to treatment, cells were starved overnight in serum free media. Cells were stimulated with indicated concentrations of nesfatin- 1 for $24 \mathrm{~h}$ at $37^{\circ} \mathrm{C} / 5 \% \mathrm{CO}_{2}$, the following day. The CellTiter-Glo Luminescent Cell Viability assay (Promega UK Ltd) was utilized, according to the manufacturer's instructions. Following incubation, proliferation was quantified via bioluminescence using a luminometer. Non-seeded wells containing media alone were included as a control.

\section{Apoptosis assay}

For fluorescent apoptosis/necrosis studies, cells were treated with nesfatin-1 and subsequently stained with $100 \mathrm{nM}$ YO-PRO-1 Iodide apoptotic stain (Molecular Probes, Invitrogen) for $15 \mathrm{~min}$ before being visualized and recorded on an Olympus BX61 fluorescent microscope (Olympus). After three $5 \mathrm{~min}$ washes with PBS, the slides were mounted with Vectashield mounting medium containing DAPI counter stain (Vector Laboratories Ltd, Peterborough, UK). The slides were examined under an oil immersion objective $(40 \times)$ and fluorescent signals were analysed using a Zeiss Axioskop 2 microscope (Carl Zeiss Microscopy Ltd, Cambridge, UK) equipped with a cooled CCD camera (CoolSNAP; Photometrics, Tucson, AZ, USA) controlled by a Power Macintosh computer. For each treatment group, between ten and 15 random fields were selected and examined.

\section{Cellular DNA fragmentation assay}

Levels of apoptotic cell death were measured by a quantitative sandwich enzyme immunoassay using a commercial kit i.e. Cellular DNA fragmentation ELISA (Roche Diagnostics Ltd). Cells were labeled with bromodeoxyuridine (BrdU) overnight prior to treatments. Following BrdU incorporation, the cells were washed with PBS and incubated with media containing various treatments for $24 \mathrm{~h}$. At the end of the indicated timepoints, cells were permeabilized to release the cytoplasmic DNA fragments into the supernatant. The supernatants

Published by Bioscientifica Ltd. 
were centrifuged at $300 \boldsymbol{g}$ for $10 \mathrm{~min}$ to bring down the high molecular weight genomic DNA, the low molecular weight BrdU-labeled fragmented DNA released into the supernatants were measured by an ELISA reader (Microplate reader, Molecular Devices, Wokingham, UK) using antibodies against DNA and BrdU.

\section{Calcium measurements}

H295R cells were grown to confluence and plated in 96-well black-walled tissue culture plates $\sim 24 \mathrm{~h}$ prior to experiments. Relative levels of intracellular $\mathrm{Ca}^{2+}$ were measured using the Fluo-4 NW calcium assay kit (Molecular Probes, Invitrogen, Paisley, UK). Cells were loaded with fluo-4 AM in the presence of $2.5 \mathrm{mM}$ probenicid in a commercial phenol-free, magnesium-free Hank's balanced salt solution (HBSS; Invitrogen). The cells were stimulated with various concentrations of nesfatin- 1 and fluorescence was measured using a fluorescence plate reader (Tecan GENios, Männedorf, Switzerland; excitation at $485 \mathrm{~nm}$ and emission at $520 \mathrm{~nm}$ ) at room temperature.

\section{Statistical analysis}

Data presented in this manuscript are means \pm s.E.M. from three or four different experiments. Data were analyzed by either Student's $t$-test or ANOVA (post hoc analysis: Tukey's test), according to the number of groups compared. All statistical analyses were performed using GraphPad Prism 6.0 (GraphPad Software, Inc., San Diego, CA, USA). $P<0.05$ was considered significant.

\section{Results}

\section{Expression of NUCB2 gene and nesfatin-1 protein in human adrenal gland, rat adrenal gland and in human adrenocortical (H295R) cells}

The expression of NUCB2 gene and protein in human adrenal gland and human adrenocortical (H295R) cells was analysed by RT-PCR and western blotting. NUCB2 gene and protein are expressed in both human adrenal gland and in H295R cells; human adipose tissue was used as positive control (Fig. 1A and B). In order to evaluate further the cellular distribution of nesfatin-1 protein in H295R cells, we employed immunohistochemistry using specific antibodies to detect the intracellular distribution of nesfatin-1 in H295R cells. Intense cytoplasmic staining demonstrated the presence of nesfatin- 1 protein in the cytoplasm (Fig. 1C). Within rat adrenal gland section nesfatin-1 immuno-positive substances were present in the cytoplasm of all the zones of adrenal cortex and whilst no reaction was observed in adrenal medulla (Fig. 1D, E, F and $G)$. No apparent expression was evident in the negative controls, confirming staining specificity.

\section{Effects of nesfatin-1 on cortisol and aldosterone secretion from H295R cells}

ELISAs were employed to measure cortisol production and aldosterone secretion from H295R cells following stimulation with nesfatin-1 $(100 \mathrm{nM})$ in a time dependent manner. It was evident from our study that nesfatin- 1 did not induce any significant changes in either cortisol or aldosterone production compared to basal levels across the time points measured $(6,24,36$ and $48 \mathrm{~h})$. Forskolin $(10 \mu \mathrm{M})$ was used as positive control for cortisol secretion, which showed a time dependent increase in cortisol secretion reaching significance at $24 \mathrm{~h}$ (Fig. 2A, $\left.{ }^{* *} P<0.01\right)$. Angiotensin II $(100 \mathrm{nM})$ was used as a positive control for aldosterone secretion, which also showed a time dependent increase in aldosterone secretion reaching significance at $24 \mathrm{~h}$ (Fig. $2 \mathrm{~B},{ }^{* *} \mathrm{P}<0.01$ ).

\section{Effect of nesfatin-1 stimulation on StAR gene expression in H295R cells}

Regulation of StAR mRNA expression and translocation into the mitochondria is the first key rate-limiting step in steroid biosynthesis and StAR deficiency is associated with pathophysiology of lipoid congenital adrenal hyperplasia (Manna \& Stocco 2005). To assess the relative changes in StAR gene expression following nesfatin-1 treatment, H295R cells were treated with nesfatin-1 (100 nM) for 4 and $24 \mathrm{~h}$. Following agonist stimulation the relative changes in StAR mRNA expression were compared by RTPCR analysis, which showed no significant changes in StAR expression following nesfatin-1 stimulation (Fig. 2C, $P>0.05)$. Stimulation with angiotensin II $(100 \mathrm{nM})$ used as positive control for $24 \mathrm{~h}$ induced significant increase in StAR mRNA expression (Fig. 2B, ${ }^{* * *} P<0.001$ ).

\section{Effect of nesfatin-1 on H295R and Y1 cell viability}

Cell proliferation in response to nesfatin- $1(5,50,100 \mathrm{nM})$ stimulation was measured using the CellTiter-Glo Luminescent Cell Viability assay (Promega UK Ltd) at $24 \mathrm{~h}$. Control cells were treated with the same amount of vehicle. Nesfatin-1 significantly inhibited growth of H295R (Fig. 3A, ${ }^{* *} P<0.01$ ) and Y1 cells (Fig. 3E,

Published by Bioscientifica Ltd 
A

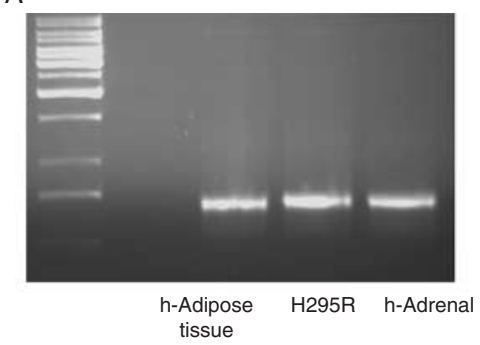

B
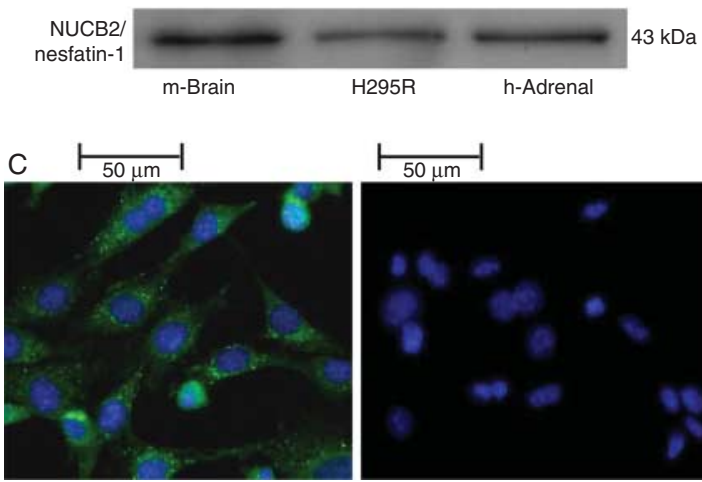

H295R+Nesfatin-1 staining

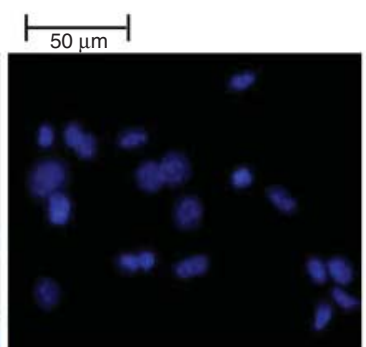

Negative staining

\section{Figure 1}

Expression of NUCB2 mRNA, nesfatin-1 protein expression in H295R cells, human adrenal gland and rat adrenal gland. (A) RT-PCR showing the presence of NUCB2 mRNA, (B) western blotting showing nesfatin-1 protein expression in human adipose tissue (h-AT), H295R cells and human adrenal gland (h-AG). Expression data shown in the figure is based on our findings from a sample size of 6. (C) Immunofluorescence of nesfatin-1 in the H295R cell line. (D, E, F and G) Immunohistochemistry showing the presence of nesfatin-1 protein localization in rat adrenal gland. Immunopositive

$\left.{ }^{*} P<0.05\right)$ after $24 \mathrm{~h}$ compared to vehicle alone. Data points were determined from three independent experiments, each performed in quadruplicate samples and the data points are expressed as percentage decrease over control cells.

\section{Effect of nesfatin-1 on H295R cell apoptosis}

Given the previous data, we next assessed if nesfatin-1 promoted apoptosis using a standard DNA fragmentation assay and YO-PRO-1 staining methods. The number of cells stained with YO-PRO-1 (apoptotic green cells) was significantly higher in the nesfatin-1 stimulated group compared to control cells (Fig. 3B). Therefore, we further evaluated the effects of nesfatin- $1(5,50$ and $100 \mathrm{nM})$ on H295R cells apoptosis using the DNA fragmentation assay. Nesfatin-1 induced a concentration dependent increase in apoptosis of H295R cells compared to control cells at $24 \mathrm{~h}$ (Fig. $3 \mathrm{D},{ }^{* *} P<0.01$ ). Camptothecin, a known drug to induce apoptosis in various cellular models was used as
D

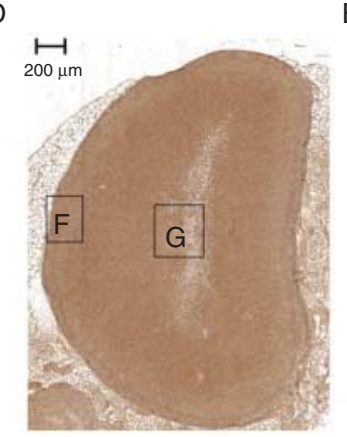

E

$\mathrm{F}$

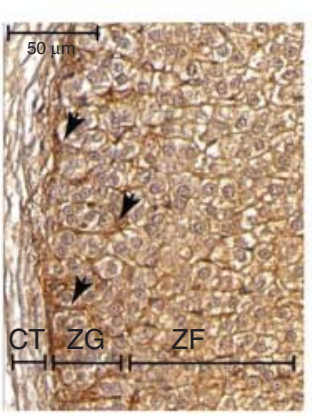

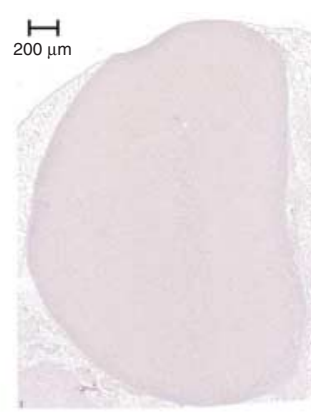

G

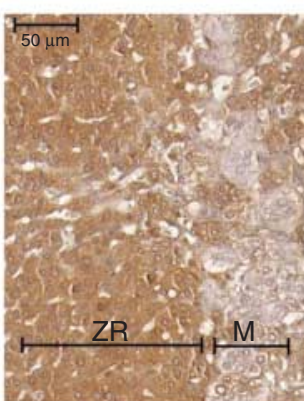

substances are visible in cytoplasm of adrenocortical cells and in endothelial cells of the cortex. D: cross section through the entire rat adrenal gland. (E) Control section. (F) Higher magnification of the zona glomerulosa (ZG) and zona fasciculata (ZF) (region shown in D),

$\mathrm{CT}$ - connective tissue capsule. Arrowheads show intense positive reaction in endothelial cells of the capillary bed; G: higher magnification of the zona reticularis (ZR) and medulla (M) (region shown in D). Sections counterstained with haematoxylin. Magnifications defined by scale bars.

a positive control for the assay. Camptothecin $(2 \mu \mathrm{M})$ induced a significant increase in apoptosis (Fig. 3D, $\left.{ }^{\star * \star} P<0.001\right)$. However, when nesfatin-1 was co-incubated with camptothecin, there was no synergistic or additive effects (Fig. 3D, P>0.05). Stimulation of Y1 cells with nesfatin-1 induced apoptosis similar to that observed in H295R cells (Fig. 3F, ${ }^{\star} P>0.05$ ).

\section{Effects of nesfatin-1 on pro- and anti-apoptotic gene expression in H295R cells}

Given the preceding data, we assessed the relative changes in pro- and anti-apoptotic genes expression following nesfatin-1 treatment in H295R cells. H295R cells were stimulated with nesfatin-1 (100 nM) for $4 \mathrm{~h}$, and the relative changes in expression of Bax, BCL-XL, BCL-2 and p53 mRNA expression was assessed by RT-PCR analysis. There was a significant increase in Bax (Fig. $\left.4 \mathrm{~A},{ }^{*} P<0.05\right)$ and significant reductions in BCL-XL (Fig. $4 \mathrm{~B},{ }^{* *} P<0.01$ ) and of BCL-2 (Fig. $4 \mathrm{C},{ }^{\star} P<0.05$ ) mRNA expression following

Published by Bioscientifica Ltd. 


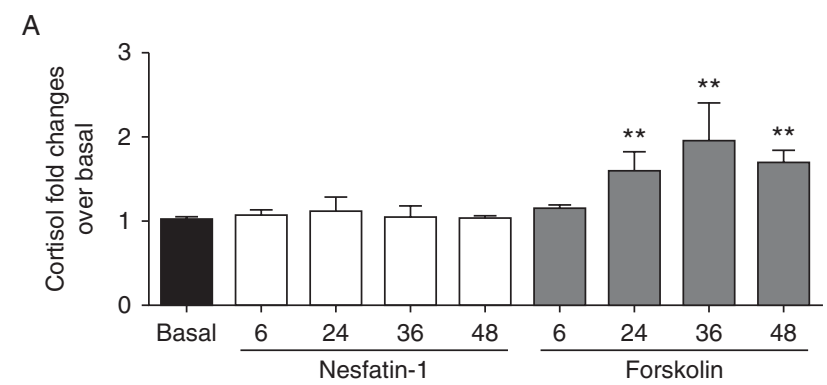

B
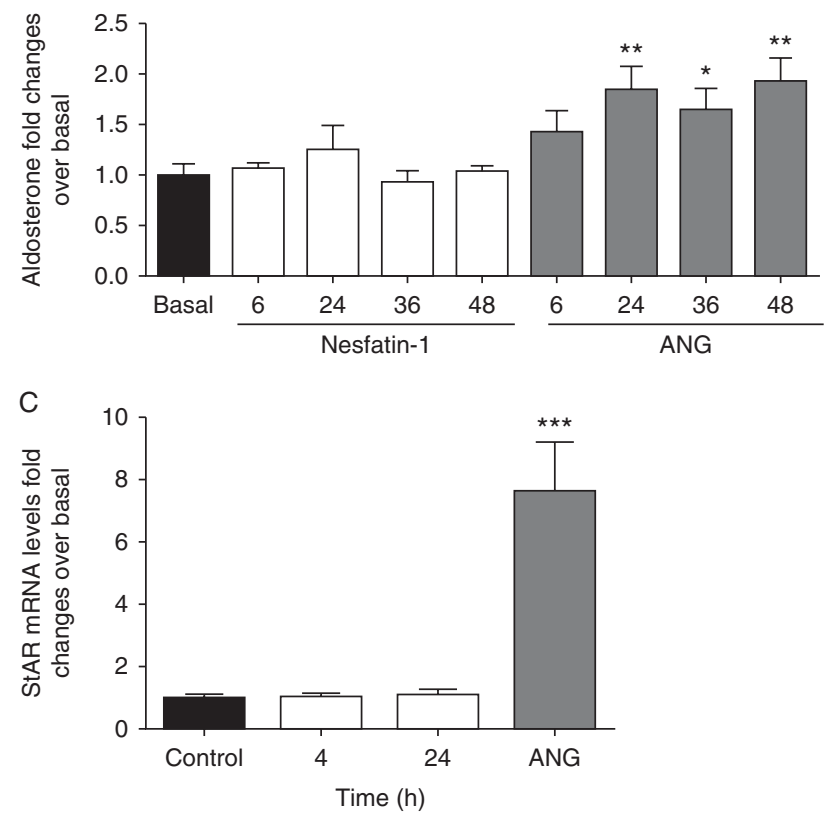

Figure 2

Effects of nesfatin-1 on (A) cortisol and (B) aldosterone secretion from H295R cells. H295R cells (four replicates) were stimulated with nesfatin-1 $(100 \mathrm{nM})$, forskolin $(10 \mu \mathrm{M})$ or angiotensin II (Ang II) $(100 \mathrm{nM})$ at 6, 24, 36 and $48 \mathrm{~h}$. At various timepoints media was collected for cortisol and aldosterone assay, and protein lysates from each treatment group were collected for normalization of steroid estimation. (C) Effects of nesfatin-1 on STAR protein (StAR) mRNA levels in H295R cells. Cells were cultured for the indicated periods in the presence or absence of nesfatin-1 (100 nM). StAR mRNA expression levels were normalized against GAPDH mRNA expression. Data are expressed as mean \pm s.E.M., from four independent experiments. ${ }^{*} P<0.05$ and $* * P<0.01$.

nesfatin-1 stimulation. However, there were no significant changes in p53 mRNA expression (Fig. 4D, $P>0.05$ ).

\section{Effects of nesfatin-1 on intracellular $\mathrm{Ca}^{2+}$ levels in H295R cells}

Elevation of intracellular calcium through release from intracellular stores such as the endoplasmic reticulum (ER) and a concomitant influx of extracellular $\mathrm{Ca}^{2+}$ into the cell (due to the sustained depletion of $\mathrm{Ca}^{2+}$ from the ER), have been shown to initiate apoptosis (Furuya et al. 1994).
Therefore, we assessed the effects of nesfatin- 1 on intracellular $\mathrm{Ca}^{2+}$ levels in H295R cells. Nesfatin-1 did not have any significant effects on intracellular $\mathrm{Ca}^{2+}$ levels in H295R cells. Angiotensin II (100 nM), used as a positive control, showed an $\sim 2$.5-fold increase in intracellular $\mathrm{Ca}^{2+}$ levels (Fig. 5).

\section{Role of MAPK signalling pathways in nesfatin-1 mediated H295R cell proliferation and apoptosis}

MAPK signalling pathways play a vital role in regulating cell proliferation and apoptosis (Minden et al. 1994, Xia et al. 1995, Dhillon et al. 2007). We employed western blotting to study the effect of nesfatin-1 on key MAPK signalling pathways i.e. $\mathrm{ERK}_{1 / 2}, \mathrm{p} 38$ and JNK1/2 pathways. H295R cells were stimulated with nesfatin-1 (100 nM) for $2.5,5,15,30$ and $60 \mathrm{~min}$. Nesfatin-1 stimulation decreased $\mathrm{ERK}_{1 / 2}$ phosphorylation, and increased p38 and JNK1/2 phosphorylation in H295R cells (Fig. 6). The immediate, significant effects of nesfatin-1 induced activation of p38 and JNK1/2 and down regulation of ERK1/2 suggest a likely direct physiological role for these MAPK elements.

\section{Discussion}

This is the first study demonstrating the expression of NUCB2/nesfatin gene and nesfatin-1 protein in human adrenal gland and human adrenocortical cells (H295R). The distribution of nesfatin-1 in rat adrenal sections appears to be more in adrenal cortex compared to adrenal medulla as observed by immunohistochemistry. Due to abundance of lipid droplets content in zona glomerulosa (ZG) and zona fasciculata (ZF), immunopositive signal seems to be weaker and more diffused in these zones in comparison to zona reticularis (ZR), where the entire cytoplasm is stained. Our results also show strong immunopositive signal in endothelial cells of the capillary bed, especially in ZG and ZF. We also present novel data of nesfatin-1's effects on steroid production, cell viability and apoptosis in human adrenocortical cells (H295R).

Stimulation of H295R cells with nesfatin-1 had no significant effects on glucocorticoid (cortisol) and mineralocorticoid secretions as well as StAR gene expression; the StAR gene encodes for the transport protein that regulates cholesterol transfer within the mitochondria, which is the rate limiting step in the production of steroid hormones. However, nesfatin-1 decreased cell proliferation and induced apoptosis in H295R cells. This is in agreement with a recent study, which showed that nesfatin-1 inhibits ovarian epithelial carcinoma cell

Published by Bioscientifica Ltd. 

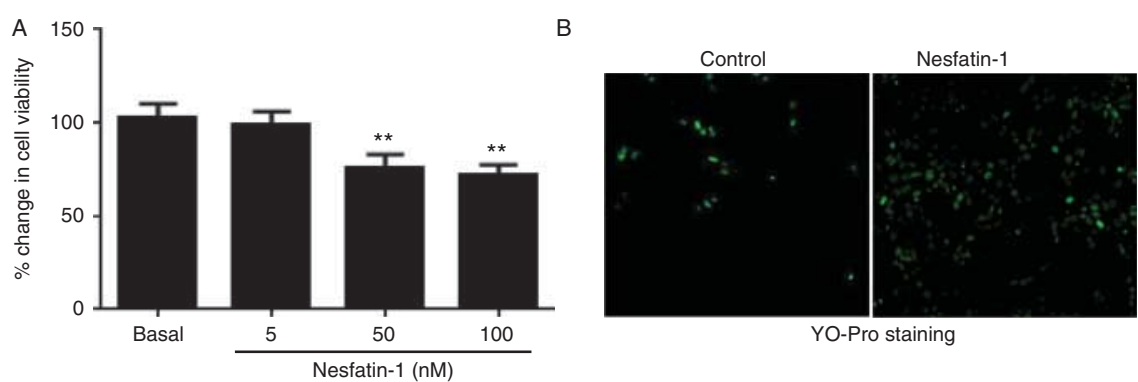

C

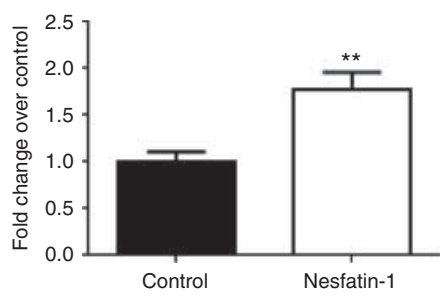

D
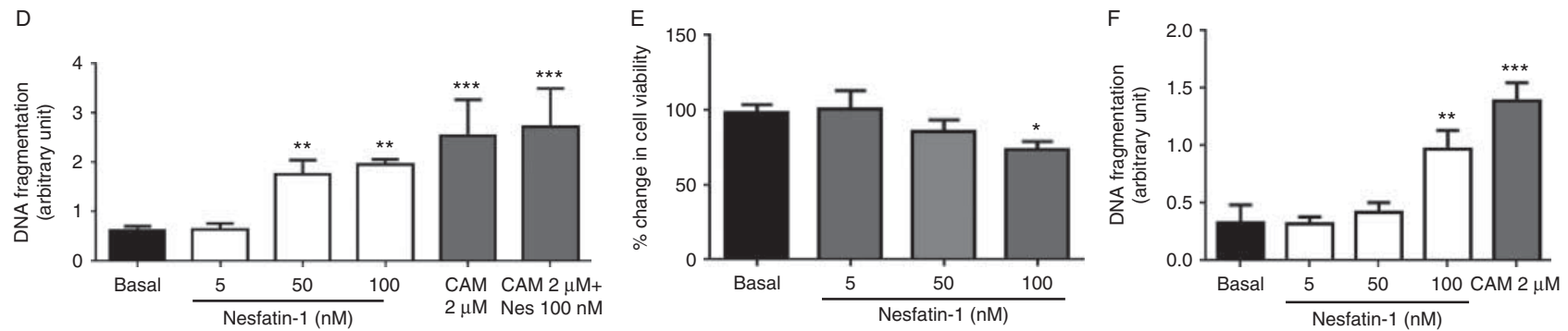

Figure 3

Following overnight serum depletion, H295R cells were stimulated with nesfatin-1 (Nes) $(5,50,100 \mathrm{nM})$ and/or camptothecin (CAM) $(2 \mu \mathrm{M})$ for $24 \mathrm{~h}$ to study the effects of nesfatin-1 on H295R (A) cell viability, (B) and YO-PRO-1 staining (apoptotic cells labeled green), (C) shows signal intensity of the YO-PRO-1 staining in control and nesfatin-1 stimulated cells quantified by ImageJ. Signal intensity of control cells was set to 1 .

proliferation (Xu et al. 2013). These effects may be tissue and cell type specific as other researchers have found conflicting results in breast cancer cell models (MCF-7 and SK-BR-3), i.e. NUCB2/nesfatin significantly increased cell proliferation as well as migration and invasion properties in MCF-7 and SK-BR-3 cells (Suzuki et al. 2012).

Apoptosis is a critical component of adrenal cortical development and remodelling. The adrenal cortex undergoes apoptosis of different zones during fetal and adult life. During postnatal adrenal cortical remodelling, the inner portion of the cortex mainly undergoes apoptosis (Wyllie et al. 1973a,b). However, in the adult human adrenal cortex, cellular apoptosis appears to be highest in the external ZG and decreased in the internal ZF and ZR.
(D) Concentration dependent effects of nesfatin-1 on DNA fragmentation data in H295R cells. (E) Concentration dependent effects of nesfatin-1 on Y1 cell viability. (F) Concentration dependent effects of nesfatin-1 on DNA fragmentation data in mouse $\mathrm{Y} 1$ cells. Data are expressed as mean \pm s.E.M., from three independent experiments, each performed in quadruplicate samples. ${ }^{*} P<0.01$ and $* * * P<0.001$.

Although the reason for this reversal of the apoptotic pattern is unknown, it does suggest that the role of apoptosis in adrenal cortical growth and remodelling may play a key role in tissue remodelling during fetal and adult life. Our findings of nesfatin-1 inducing apoptotic effects on adrenocortical cells may shed some light on the possible role of NUCB2/nesfatin in adrenal remodelling.

Apoptosis is a tightly regulated physiological process in which cell death is executed for the maintenance of a steady state homeostasis under normal physiological conditions, and for responding to various stimuli. Various regulatory proteins control these processes, and genetic aberrations in the control of the transcription of these proteins are present in all cancers (Le Beau et al. 1985,

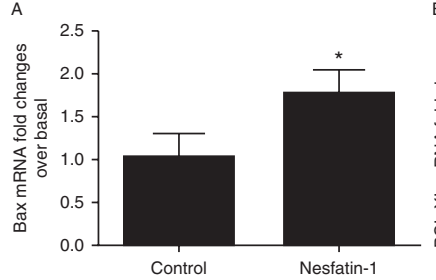

Control

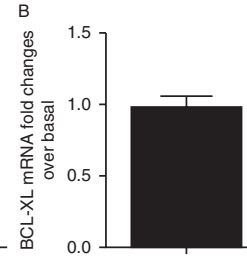

Control

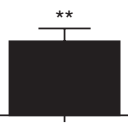

Nesfatin-1
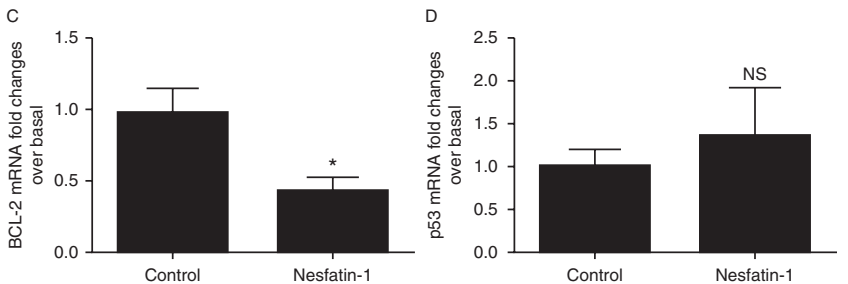

Figure 4

Effects of nesfatin-1 (100 nM) stimulation for $4 \mathrm{~h}$ on pro and anti-apoptotic genes expression in H295R cells; mRNA expression levels were normalized against GAPDH mRNA expression. Data are expressed as mean \pm s.E.M., from four independent experiments. ${ }^{*} P<0.05$ and $* \star P<0.01$.

http://joe.endocrinology-journals.org DOI: $10.1530 / \mathrm{JOE}-14-0496$
(C) 2015 Society for Endocrinology Printed in Great Britain
Published by Bioscientifica Ltd. 


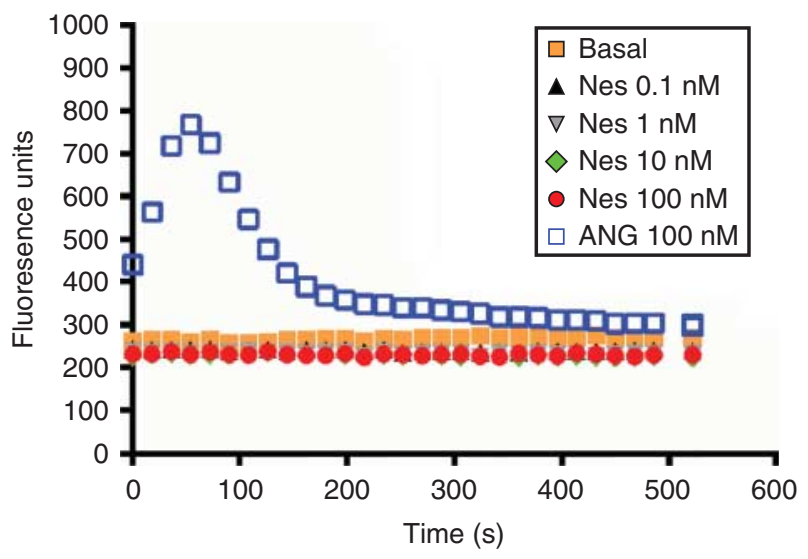

Figure 5

Effects of nesfatin-1 (Nes) $(1,10,100 \mathrm{nM})$ and/or angiotensin II (ANG) $(100 \mathrm{nM})$ on intracellular calcium levels in H295R cells. H295R cells were cultured as described in the methods section. Data are expressed as mean \pm s.E.M., from four independent experiments. Time in (s). A full colour version of this figure is available at http://dx.doi.org/10.1530/JOE-14-0496.

Adams \& Cory 1998). The members of BCL-2 proteins are potent regulators of the apoptotic process (Adams \& Cory 1998, Borner 2003, Donovan \& Cotter 2004, Sharpe et al. 2004). They consist of both pro- and anti-apoptotic genes that induce opposing effects on mitochondria, including the anti-apoptotic protein Bcl-2 and the pro-apoptotic proteins Bax: BCL-2 family members have the ability to heterodimerize and modify each other's function. Earlier studies have demonstrated an increase in p53 expression and Bax-BCL-2 ratio favouring p53 dependent Bax induced apoptosis (McDonnell et al. 1992, Antonsson \& Martinou 2000). In addition, p53 has a transcriptionindependent role in apoptosis induction by promoting both activation and insertion of Bax into the mitochondrial membrane (Miyashita \& Reed 1995). Thus, we investigated whether nesfatin-1 induced apoptosis in H295R cells could be by modulation of the expression of Bax, BCL-XL, BCL-2 and p53 genes. Our results suggest that nesfatin-1 induced apoptosis in H295R cells involves the Bax, BCL-XL and BCL-2 genes. The relevance of these findings on adrenal physiology remains to be explored further. Alterations in intracellular calcium homeostasis due to increased calcium influx or inhibition of calcium efflux is one of the early crucial events involved in apoptosis (Orrenius et al. 1992). Therefore, we studied the effects of nesfatin-1 on intracellular calcium levels in H295R cells. We found no significant changes in intracellular calcium levels suggesting that nesfatin- 1 induced apoptosis in H295R cells maybe calcium independent. Further experiments are needed to clarify this point. Notably, calcium independent apoptosis has previously been observed in prostate cancer and in cervical cancer cells (Wang et al. 2004, Savino et al. 2006).

MAPK are crucial for transmission of signal from cell surface receptors to the transcriptional machinery located in the nucleus (Cobb \& Goldsmith 1995, Hill \& Treisman 1995). MAPK signalling pathways are pivotal in the regulation of cell growth, survival, cell cycle regulation, differentiation and gene expression (Johnson \& Vaillancourt 1994). We report for the first time that nesfatin-1 stimulation decreased $\mathrm{ERK}_{1 / 2}$ phosphorylation, and increased p38 and JNK1/2 phosphorylation in H295R cells.

These findings are in agreement with previous reports from various cellular models that have reported the
A

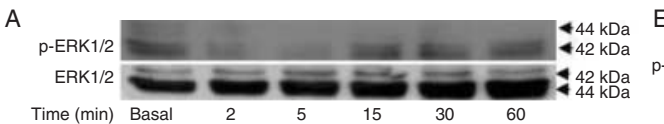

B
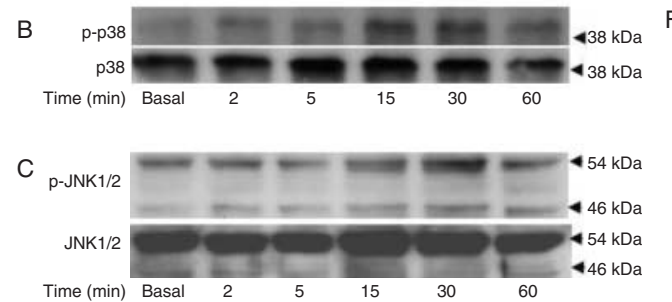

Figure 6

Effects of nesfatin-1 (100 nM) stimulation on ERK1/2, p38 and JNK1/2 protein phosphorylation and corresponding total protein expressions in $\mathrm{H} 295 \mathrm{R}$ cells at 2.5, 5, 15, 30 and $60 \mathrm{~min}$. Western blot analysis of protein extracts from $\mathrm{H} 295 \mathrm{R}$ cells demonstrate that the antibody against $\mathrm{p}$-ERK1/2, total ERK1/2, p-p38, total p38, p-JNK1/2 and total JNK1/2 recognized bands
D

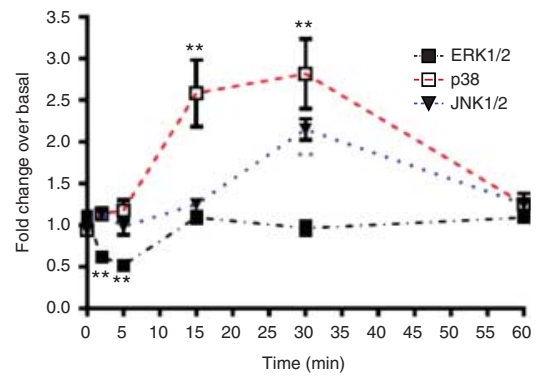

with apparent molecular weights of $42,44,43,43,46$ and $54 \mathrm{kDa}$, respectively. Data are expressed as mean \pm s.E.M., from three independent experiments. $* * P<0.01$ and $* * * P<0.001$. A full colour version of this figure is available at http://dx.doi.org/10.1530/JOE-14-0496. 
activation of p38 and JNK1/2 to be associated with programmed cell death and/or necrosis pathways, and the activation of $\mathrm{ERK}_{1 / 2}$ with cell survival pathways (Minden et al. 1994, Xia et al. 1995, Dhillon et al. 2007). Future studies should involve inhibiting p38 and JNK1/2 pathways. It would also be interesting to evaluate the effects of NUCB2/nesfatin in other cancer cell models.

In conclusion, we found that NUCB2/nesfatin is expressed in human adrenal gland and human adrenocortical cells. Stimulation with nesfatin-1 inhibits adrenocortical cell growth and promotes apoptosis, potentially via the involve-

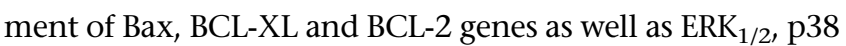
and JNK1/2 signalling cascades. This has implications for understanding the role of NUCB2/nesfatin in adrenal zonal development. NUCB2/nesfatin may also be a therapeutic target for adrenal cancer. However, further studies using in vivo models are needed to clarify these concepts.

\section{Declaration of interest}

The authors declare that there is no conflict of interest that could be perceived as prejudicing the impartiality of the research reported.

\section{Funding}

This work was supported by the General Charities of the City of Coventry.

\section{Author contribution statement}

$M \mathrm{R}$ researched data, contributed to discussion and wrote the manuscript and reviewed/edited the manuscript. B K T contributed to discussion, wrote the manuscript and reviewed/edited the manuscript. $\mathrm{M} \mathrm{K}, \mathrm{J} \mathrm{H}$ and $\mathrm{V} \mathrm{H} \mathrm{P}$ researched data and reviewed/edited the manuscript. J K, H L and H S R contributed to discussion and reviewed/edited the manuscript.

\section{Acknowledgements}

H S R acknowledges S Waheguru, University of Warwick, for his continual support.

\section{References}

Adams JM \& Cory S 1998 The Bcl-2 protein family: arbiters of cell survival. Science 281 1322-1326. (doi:10.1126/science.281.5381.1322)

Adya R, Tan BK, Chen J \& Randeva HS 2012 Protective actions of globular and full-length adiponectin on human endothelial cells: novel insights into adiponectin-induced angiogenesis. Journal of Vascular Research 49 534-543. (doi:10.1159/000338279)

Antonsson B \& Martinou JC 2000 The Bcl-2 protein family. Experimental Cell Research 256 50-57. (doi:10.1006/excr.2000.4839)

Borner C 2003 The Bcl-2 protein family: sensors and checkpoints for lifeor-death decisions. Molecular Immunology 39 615-647. (doi:10.1016/ S0161-5890(02)00252-3)

Cetinkaya H, Karagöz B, Bilgi O, Ozgün A, Tunçel T, Emirzeoğlu L, Top C \& Kandemir EG 2013 Nesfatin-1 in advanced lung cancer patients with weight loss. Regulatory Peptides 181 1-3. (doi:10.1016/j.regpep. 2012.11.005)

Cobb MH \& Goldsmith EJ 1995 How MAP kinases are regulated. Journal of Biological Chemistry 270 14843-14846. (doi:10.1074/jbc.270.25.14843)

Dhillon AS, Hagan S, Rath O \& Kolch W 2007 MAP kinase signalling pathways in cancer. Oncogene 26 3279-3290. (doi:10.1038/sj.onc.1210421)

Donovan M \& Cotter TG 2004 Control of mitochondrial integrity by Bcl-2 family members and caspase-independent cell death. Biochimica et Biophysica Acta 1644 133-147. (doi:10.1016/j.bbamcr.2003.08.011)

Ducsay CA, Hess DL, McClellan MC \& Novy MJ 1991 Endocrine and morphological maturation of the fetal and neonatal adrenal cortex in baboons. Journal of Clinical Endocrinology and Metabolism 73 385-395. (doi:10.1210/jcem-73-2-385)

Ehrhart-Bornstein M, Arakelyan K, Krug AW, Scherbaum WA \& Bornstein SR 2004 Fat cells may be the obesity-hypertension link: human adipogenic factors stimulate aldosterone secretion from adrenocortical cells. Endocrine Research 30 865-870. (doi:10.1081/ERC-200044122)

Elmquist JK, Coppari R, Balthasar N, Ichinose M \& Lowell BB 2005 Identifying hypothalamic pathways controlling food intake, body weight, and glucose homeostasis. Journal of Comparative Neurology 493 63-71. (doi:10.1002/cne.20786)

Furuya Y, Lundmo P, Short AD, Gill DL \& Isaacs JT 1994 The role of calcium, $\mathrm{pH}$, and cell proliferation in the programmed (apoptotic) death of androgen-independent prostatic cancer cells induced by thapsigargin. Cancer Research 54 6167-6175.

Hill CS \& Treisman R 1995 Transcriptional regulation by extracellular signals: mechanisms and specificity. Cell 80 199-211. (doi:10.1016/ 0092-8674(95)90403-4)

Johnson GL \& Vaillancourt RR 1994 Sequential protein kinase reactions controlling cell growth and differentiation. Current Opinion in Cell Biology 6 230-238. (doi:10.1016/0955-0674(94)90141-4)

Kargi AY \& Iacobellis G 2014 Adipose tissue and adrenal glands: novel pathophysiological mechanisms and clinical applications. International Journal of Endocrinology 2014 614074. (doi:10.1155/2014/614074)

Keegan CE \& Hammer GD 2002 Recent insights into organogenesis of the adrenal cortex. Trends in Endocrinology and Metabolism 13 200-208. (doi:10.1016/S1043-2760(02)00602-1)

Kirschner LS 2002 Signaling pathways in adrenocortical cancer. Annals of the New York Academy of Sciences 968 222-239. (doi:10.1111/ j.1749-6632.2002.tb04338.x)

Könczöl K, Bodnár I, Zelena D, Pintér O, Papp RS, Palkovits M, Nagy GM \& Tóth ZE 2010 Nesfatin-1/NUCB2 may participate in the activation of the hypothalamic-pituitary-adrenal axis in rats. Neurochemistry International 57 189-197. (doi:10.1016/j.neuint.2010.04.012)

Le Beau MM, Westbrook CA, Diaz MO, Rowley JD \& Oren M 1985 Translocation of the p53 gene in $\mathrm{t}(15 ; 17)$ in acute promyelocytic leukaemia. Nature 316 826-828. (doi:10.1038/316826a0)

Lewandowski KC, Stojanovic N, Bienkiewicz M, Tan BK, Prelevic GM, Press M, Tuck S, O'Hare PJ \& Randeva HS 2008 Elevated concentrations of retinol-binding protein-4 (RBP-4) in gestational diabetes mellitus: negative correlation with soluble vascular cell adhesion molecule-1 (sVCAM-1). Gynecological Endocrinology 24 300-305. (doi:10.1080/ 09513590802141052)

Maisey MN \& Lessof MH 1969 Thyroid function in Addison's disease. BMJ 3 392-393. (doi:10.1136/bmj.3.5667.392)

Manna PR \& Stocco DM 2005 Regulation of the steroidogenic acute regulatory protein expression: functional and physiological consequences. Current Drug Targets. Immune, Endocrine and Metabolic Disorders 5 93-108. (doi:10.2174/1568008053174714)

McDonnell TJ, Troncoso P, Brisbay SM, Logothetis C, Chung LW, Hsieh JT, Tu SM \& Campbell ML 1992 Expression of the protooncogene bcl-2 in the prostate and its association with emergence of androgenindependent prostate cancer. Cancer Research 52 6940-6944.

Minden A, Lin A, Smeal T, Dérijard B, Cobb M, Davis R \& Karin M 1994 c-Jun N-terminal phosphorylation correlates with activation of the

Published by Bioscientifica Ltd. 
JNK subgroup but not the ERK subgroup of mitogen-activated protein kinases. Molecular and Cellular Biology 14 6683-6688.

Miyashita T \& Reed JC 1995 Tumor suppressor p53 is a direct transcriptional activator of the human bax gene. Cell 80 293-299. (doi:10.1016/0092-8674(95)90513-8)

Oh-I S, Shimizu H, Satoh T, Okada S, Adachi S, Inoue K, Eguchi H, Yamamoto M, Imaki T, Hashimoto K et al. 2006 Identification of nesfatin-1 as a satiety molecule in the hypothalamus. Nature $\mathbf{4 4 3}$ 709-712. (doi:10.1038/nature05162)

Orrenius S, McCabe MJ Jr \& Nicotera P $1992 \mathrm{Ca}(2+)$-dependent mechanisms of cytotoxicity and programmed cell death. Toxicology Letters 64-65. Spec No. 357-364. (doi:10.1016/0378-4274(92)90208-2)

Pfaffl MW 2001 A new mathematical model for relative quantification in real-time RT-PCR. Nucleic Acids Research 29 e45. (doi:10.1093/ nar/29.9.e45)

Rainey WE, Bird IM \& Mason JI 1994 The NCI-H295 cell line: a pluripotent model for human adrenocortical studies. Molecular and Cellular Endocrinology 100 45-50. (doi:10.1016/0303-7207(94)90277-1)

Ramanjaneya M, Chen J, Brown JE, Tripathi G, Hallschmid M, Patel S, Kern W, Hillhouse EW, Lehnert H, Tan BK et al. 2010 Identification of nesfatin-1 in human and murine adipose tissue: a novel depot-specific adipokine with increased levels in obesity. Endocrinology 151 3169-3180. (doi:10.1210/en.2009-1358)

Randeva HS, Tan BK, Weickert MO, Lois K, Nestler JE, Sattar N \& Lehnert H 2012 Cardiometabolic aspects of the polycystic ovary syndrome. Endocrine Reviews 33 812-841. (doi:10.1210/en.2009-1358)

Savino JA III, Evans JF, Rabinowitz D, Auborn KJ, Carter TH, Evans JF, Rabinowitz D, Auborn KJ \& Carter TH 2006 Multiple, disparate roles for calcium signaling in apoptosis of human prostate and cervical cancer cells exposed to diindolylmethane. Molecular Cancer Therapeutics 5 556-563. (doi:10.1158/1535-7163.MCT-05-0355)

Sharpe JC, Arnoult D \& Youle RJ 2004 Control of mitochondrial permeability by Bcl-2 family members. Biochimica et Biophysica Acta 1644 107-113. (doi:10.1016/j.bbamcr.2003.10.016)

Shimizu H, Oh-I S, Hashimoto K, Nakata M, Yamamoto S, Yoshida N, Eguchi H, Kato I, Inoue K, Satoh T et al. 2009 Peripheral administration of nesfatin-1 reduces food intake in mice: the leptin-independent mechanism. Endocrinology 150 662-671. (doi:10.1210/en.2008-0598)

Stengel A \& Taché Y 2011 Minireview: nesfatin-1-an emerging new player in the brain-gut, endocrine, and metabolic axis. Endocrinology 152 4033-4038. (doi:10.1210/en.2011-1500)
Sucheston ME \& Cannon MS 1968 Development of zonular patterns in the human adrenal gland. Journal of Morphology 126 477-491. (doi:10.1002/jmor.1051260408)

Suzuki S, Takagi K, Miki Y, Onodera Y, Akahira J, Ebata A, Ishida T, Watanabe M, Sasano H \& Suzuki T 2012 Nucleobindin 2 in human breast carcinoma as a potent prognostic factor. Cancer Science $\mathbf{1 0 3}$ 136-143. (doi:10.1111/j.1349-7006.2011.02119.x)

Tan BK, Adya R, Shan X, Syed F, Lewandowski KC, O'Hare JP \& Randeva HS 2009 Ex vivo and in vivo regulation of lipocalin-2, a novel adipokine, by insulin. Diabetes Care 32 129-131. (doi:10.2337/dc08-1236)

Tan BK, Hallschmid M, Kern W, Lehnert H \& Randeva HS 2011 Decreased cerebrospinal fluid/plasma ratio of the novel satiety molecule, nesfatin-1/NUCB-2, in obese humans: evidence of nesfatin-1/NUCB-2 resistance and implications for obesity treatment. Journal of Clinical Endocrinology and Metabolism 96 E669-E673. (doi:10.1210/jc.2010-1782)

Wang H, Chen X \& Bai X 2004 Hepatic cell apoptosis was triggerred by HBx accumulation and independent on verapamil. Journal of Huazhong University of Science and Technology. Medical Sciences 24 281-283. (doi:10.1007/BF02832013)

Wyllie AH, Kerr JF \& Currie AR 1973a Cell death in the normal neonatal rat adrenal cortex. Journal of Pathology 111 255-261. (doi:10.1002/path. 1711110406)

Wyllie AH, Kerr JF, Macaskill IA \& Currie AR 1973b Adrenocortical cell deletion: the role of ACTH. Journal of Pathology 111 85-94. (doi:10.1002/path.1711110203)

Xia Z, Dickens M, Raingeaud J, Davis RJ \& Greenberg ME 1995 Opposing effects of ERK and JNK-p38 MAP kinases on apoptosis. Science 270 1326-1331. (doi:10.1126/science.270.5240.1326)

Xu Y, Pang X, Dong M, Wen F \& Zhang Y 2013 Nesfatin-1 inhibits ovarian epithelial carcinoma cell proliferation in vitro. Biochemical and Biophysical Research Communications 440 467-472. (doi:10.1016/j.bbrc.2013.06.001)

Zhang H, Qi C, Li L, Luo F \& Xu Y 2013a Clinical significance of NUCB2 mRNA expression in prostate cancer. Journal of Experimental \& Clinical Cancer Research 32 56. (doi:10.1186/1756-9966-32-56)

Zhang H, Qi C, Wang A, Yao B, Li L, Wang Y \& Xu Y 2013b Prognostication of prostate cancer based on NUCB2 protein assessment: NUCB2 in prostate cancer. Journal of Experimental \& Clinical Cancer Research 3277. (doi:10.1186/1756-9966-32-77)

Zhang H, Qi C, Wang A, Li L \& Xu Y 2014 High expression of nucleobindin 2 mRNA: an independent prognostic factor for overall survival of patients with prostate cancer. Tumour Biology 35 2025-2028. (doi:10.1007/s13277-013-1268-z)

Received in final form 24 March 2015

Accepted 30 March 2015

Accepted Preprint published online 13 March 2015 http://joe.endocrinology-journals.org DOI: 10.1530/JOE-14-0496
(C) 2015 Society for Endocrinology Printed in Great Britain 